\title{
PHARMACOKINETIC PROFILE AND INCURRED ESOMEPRAZOLE SAMPLE STABILITY IN PLASMA USING HIGH-PERFORMANCE LIQUID CHROMATOGRAPHY - PHOTODIODE ARRAY
}

\author{
YAHDIANA HARAHAP ${ }^{1 *}$, AHMAD FARIS ${ }^{1}$, SUNARSIH ${ }^{2}$ \\ ${ }^{1}$ Faculty of Pharmacy, Universitas Indonesia, Depok 16424, West Java, Indonesia. ${ }^{2}$ Dea Medica Clinic, Bogor, 16961, Indonesia. \\ Email: yahdiana03@yahoo.com
}

Received 12 October 2018, Revised and Accepted 27 February 2019

\section{ABSTRACT}

Objective: Esomeprazole (ESO) is one of the proton-pump inhibitors and is used to treat gastroesophageal reflux. It is sensitive to low pH, heat, moisture, and oxidation, which often means that ESO in clinical samples is degraded at the time of storage, affecting analysis results. This study aimed to analyze the in vivo stability of ESO in subjects' plasma samples by testing the incurred sample stability (ISS) of ESO in plasma following 7,14 , and 28 days of storage at two concentrations close to $\mathrm{C}_{\max }$ and one concentration in the elimination phase.

Methods: Samples were analyzed using high-performance liquid chromatography with a $\mathrm{C}_{18}$ column with detection at $300 \mathrm{~nm}$ using a photodiode array detector. Lansoprazole was used as an internal standard.

Results: The ESO pharmacokinetics profile in the plasma samples yielded the values of $\mathrm{C}_{\max } 704.57-1425.85 \mathrm{ng} / \mathrm{mL} ; \mathrm{t}_{\max }$ is $2.25 \mathrm{~h}$; and $\mathrm{AUC} \mathrm{C}_{0 \mathrm{t}}$ is 2444 ng.h/mL. ISS testing of plasma samples values were $6.50 \%, 5.73 \%$, and $4.57 \%$ on first $\mathrm{C}_{\max }$ concentration; $3.55 \%, 4.84 \%$, and $3.68 \%$ on $2^{\text {nd }} \mathrm{C}_{\max }$ concentration; and $4.04 \%, 4.80 \%$, and $4.98 \%$ on elimination phase concentration.

Conclusion: ISS testing results of plasma samples from six healthy subjects who were administered doses of $40 \mathrm{mg}$ of ESO stored for 28 days showed that it fulfilled the acceptance criteria $(<20 \%)$ of the 2011 EMEA Bioanalytical Guidelines with a \%diff value in all incurred samples of $6.5 \%$.

Keywords: Esomeprazole, Lansoprazole, Plasma, Incurred sample, High-performance liquid chromatography, Photodiode array.

(c) 2019 The Authors. Published by Innovare Academic Sciences Pvt Ltd. This is an open access article under the CC BY license (http://creativecommons. org/licenses/by/4. 0/) DOI: http://dx.doi.org/10.22159/ijap.2019.v11s1.18359

\section{INTRODUCTION}

Esomeprazole (ESO) is a proton-pump inhibitor (PPI) that is suggested for the reduction of symptoms in patients with gastroesophageal reflux disease [1,2]. ESO as PPI inhibits hydrogen-potassium adenosine triphosphatase in gastric parietal cells and thus blocks gastric acid secretion $[1,2]$. ESO is the first single optical isomer PPI, derived from omeprazole, which provides better acid control than other racemic PPI and has favorable pharmacokinetic profile compared to omeprazole [3].

Method validation includes a long-term stability parameter; however, long-term in vitro stability tests do not represent the in vivo stability of a drug compound. Therefore, incurred sample stability (ISS) testing is required for clinical samples containing the analyte, which involves a reanalysis of actual clinical samples over a period of time for determining whether the analyte is stable and whether the analytical concentration is reproducible [4-6].

ESO has high sensitivity to heat and acidic medium [7,8]; therefore, it is formulated in delayed-release tablets and capsules for oral administration [8]. The issue of ESO stability should be a concern because it is sensitive to acidic $\mathrm{pH}$, heat, and moisture and is also easily oxidized $[7,9,10]$, all of which leads to poor long-term storage results on samples [7].

ESO is a highly variable drug (HVD), with coefficient of variation (CV)\% of the pharmacokinetic parameters $>30 \%$ [11]. The bioequivalence study regarding HVDs is schematically recommended using about 30 subjects to meet the requirements of the European Medicines Agency (EMA) and Food and Drug Administration [12]. Therefore, a longer time span of bioequivalence study is needed, and the storage time for samples is increased as well.
The Global Contract Research Organizations (CROs) Council for Bioanalysis recommends that ISS tests should not be routinely conducted but rather performed on a case-by-case basis when certain analytical stability issues are suspected in incurred samples [13]. Due to the known instability of ESO, an ISS analysis was performed using plasma samples in this study to be used in future bioequivalence tests.

\section{MATERIALS AND METHODS}

Materials

\section{Chemicals and reagents}

Nexium ${ }^{\circledR} 40$ mg tablet was purchased from PT AstraZeneca Indonesia (Jakarta, Indonesia). ESO magnesium trihydrate was purchased from Dr. Reddy's Laboratories Ltd. (Hyderabad, India); lansoprazole, which was used as an internal standard, was purchased from SigmaAldrich Pvt. Ltd. (Singapore). The chromatography mobile phases contained chromatographic grade methanol, sodium dihydrogen phosphate, disodium hydrogen phosphate, and acetonitrile, which were purchased from Merck KGaA (Darmstadt, Germany). Reagents such as dichloromethane, o-phosphoric acid, and sodium hydroxide were obtained from Merck KGaA (Darmstadt, Germany). Aquabidest was obtained from PT Ikapharmindo Putramas (Jakarta, Indonesia).

\section{Calibration standards and quality controls (QC)}

Stock solutions of ESO and lansoprazole were prepared at concentrations of $1.0 \mathrm{mg} / \mathrm{mL}$ in methanol. Calibration curves were prepared by spiking with an appropriate volume of methanol for producing various concentrations of 5, 25, 70, 200, 500, 800, 1200, and $1500 \mathrm{ng} / \mathrm{mL}$. QC samples were prepared at low, middle, and high ESO concentrations of 15,725 , and $1125 \mathrm{ng} / \mathrm{mL}$, respectively. 
Methods

\section{Verification and validation}

This study validated a method using high-performance liquid chromatography (HPLC) with a photodiode array detector set at a wavelength of $300 \mathrm{~nm}$. Separation was conducted on a $\mathrm{C}_{18}$ column (Waters, Sunfire ${ }^{\mathrm{TM}} 5 \mu \mathrm{m} ; 250 \mathrm{~mm} \times 4.6 \mathrm{~mm}$ ). The analysis used an isocratic separation with acetonitrile-phosphate buffer $\mathrm{pH} 7.6$ (40:60\% v/v), a column temperature of $40^{\circ} \mathrm{C}$, and a flow rate of $1.00 \mathrm{~mL} / \mathrm{min}$ for $10 \mathrm{~min}$. The method had been previously optimized and fully validated in this laboratory [14].

Verification and partial validation were performed on the method. System suitability tests were conducted using a solution containing ESO magnesium trihydrate $50 \mu \mathrm{g} / \mathrm{mL}$ and lansoprazole $50 \mu \mathrm{g} / \mathrm{mL}$. $20 \mu \mathrm{L}$ of the solution was injected onto the column, and the retention time, peak area, $\mathrm{n}$ value, and tailing factor were determined. Precision (CV \%) was determined from six repeat injections. Partial validation comprised intra-run accuracy, precision, recovery, and the linearity of the calibration curve and was determined using the criteria from the Bioanalytical guidelines (2011)

\section{Sampling}

The test articles used were plasma samples obtained from six selected healthy subjects who had been administered $40 \mathrm{mg}$ of ESO magnesium $\left(\right.$ Nexium $\left.^{\circledR}\right)$. This study was approved by the Medical Research Ethics Committee of the Faculty of Medicine, Universitas Indonesia (0036/ UN2.F1/ETIK/2018), and the subjects signed an informed consent form before participation. Blood samples were collected 12 times from 6 healthy subjects 30 min before drug administration (pre-dose) and $0.5,1,1.5,1.75,2,2.5,3,4,6,8$, and $10 \mathrm{~h}$ following the administration of $40 \mathrm{mg}$ of ESO magnesium. Blood was collected by a trained phlebotomist using Venipuncture Technique and collected in $5 \mathrm{~mL}$ anticoagulant tubes. The blood collected then was centrifuged to extract the plasma, using 11 Rcf for $20 \mathrm{~min}$. The plasma obtained was then transferred to a new container.

ESO samples were prepared from the plasma using liquid-liquid extraction. A $500 \mu \mathrm{L}$ aliquot of plasma was placed in a sample tube, and $25 \mu \mathrm{L}$ of $50 \mu \mathrm{g} / \mathrm{mL}$ lansoprazole was added. The samples were vortexed for $10 \mathrm{~s}$ and $5 \mathrm{~mL}$ of dichloromethane added before shaking on a vortex for $3 \mathrm{~min}$. The sample was then centrifuged at $1149 \mathrm{Rcf}$ for $15 \mathrm{~min}$, and $4 \mathrm{~mL}$ of the supernatant was transferred to a new container.

The supernatant is then evaporated under a stream of nitrogen gas at $40^{\circ} \mathrm{C}$ and the residue dissolved in chromatography buffer and shaken by vortex for $2 \mathrm{~min}$. After $30 \mathrm{~s}, 20 \mu \mathrm{L}$ was analyzed using HPLC.

Pharmacokinetic analysis was performed by calculating the mean $\mathrm{C}_{\max }$, $\mathrm{t}_{\text {max }}, \mathrm{t}_{1 / 2}, \mathrm{AUC}_{0-\mathrm{t}}$, and $\mathrm{AUC}_{0-\infty}$ of the subjects.

ISS testing was performed on subjects' plasma stored at $-80^{\circ} \mathrm{C}$ on days 7,14 , and 28 after collection, and samples were processed and analyzed as described previously. ISS was analyzed at two concentrations in the $\mathrm{C}_{\max }$ phase and one concentration in the elimination phase for each subject.

\section{RESULTS AND DISCUSSION}

\section{System suitability}

System suitability tests were conducted for determining the reproducibility and suitability of the selected methods. CV\% passed the required criteria $(\mathrm{CV} \leq 2 \%)$ and the results are presented in Table 1 with a representative chromatogram in Fig. 1.

\section{Calibration curve linearity}

Linearity was $r>0.99$ and accuracy was (\% diff) $\pm 20 \%$ for the lower limit of quantitation (LLOQ) and $\leq \pm 15 \%$ for other concentrations. The linear equation for the calibration curve was $y=0.0018 x+0.0017$, with $\mathrm{x}$ being ESO magnesium concentration $(\mathrm{ng} / \mathrm{mL})$ and $\mathrm{y}$ being the peak

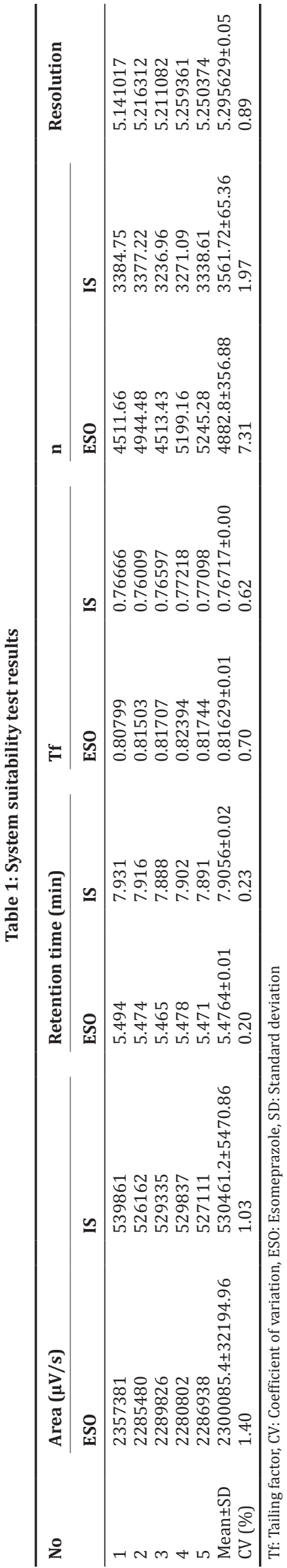


Table 2: Calibration curve concentrations

\begin{tabular}{lllllc}
\hline Concentration $(\mathbf{n g} / \mathbf{m L})$ & \multicolumn{2}{l}{ Area $(\boldsymbol{\mu V} / \mathbf{s})$} & & Measurement concentration $(\mathbf{n g} / \mathbf{m L})$ & \%diff \\
\cline { 2 - 3 } & Esomeprazole & IS & & & 0.00 \\
& 0 & 130422 & 0.0000 & 0 & 16.50 \\
5.00 & 1582 & 130394 & 0.0121 & 5.83 & 2.99 \\
200 & 5237 & 135500 & 0.0386 & 20.60 & -8.26 \\
75.00 & 16576 & 132418 & 0.1252 & 68.81 & -3.97 \\
200.00 & 45930 & 132582 & 0.3464 & 192.06 & -5.59 \\
500.00 & 124540 & 133669 & 0.9317 & 518.13 & 75.31 \\
800.00 & 189132 & 139330 & 1.3574 & 1305.26 & -4.34 \\
1200.00 & 315734 & 134666 & 2.3446 & 1434.94 & \\
1500.00 & 335618 & 130218 & 2.5774 & \\
\hline Slope (b) & Intercept (a) & $\mathbf{r}$ & $\mathbf{R}^{2}$ & & \\
\hline 0.0018 & 0.0017 & 0.9966 & 0.9931 & & \\
\hline
\end{tabular}

PAR: Peak area ratio

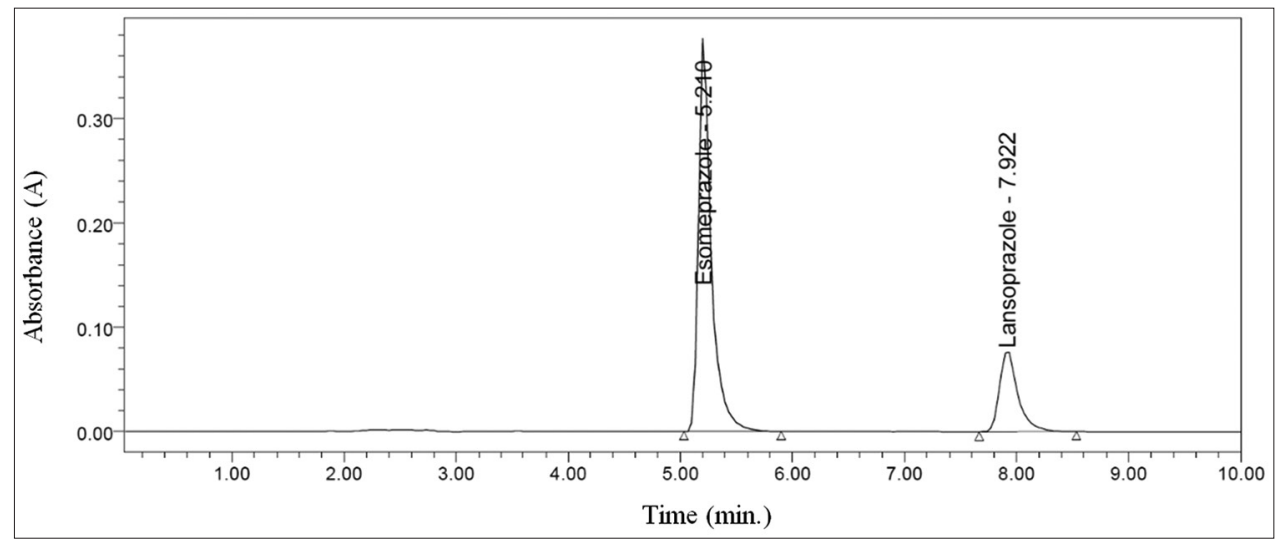

Fig. 1: Representative chromatogram for system suitability tests

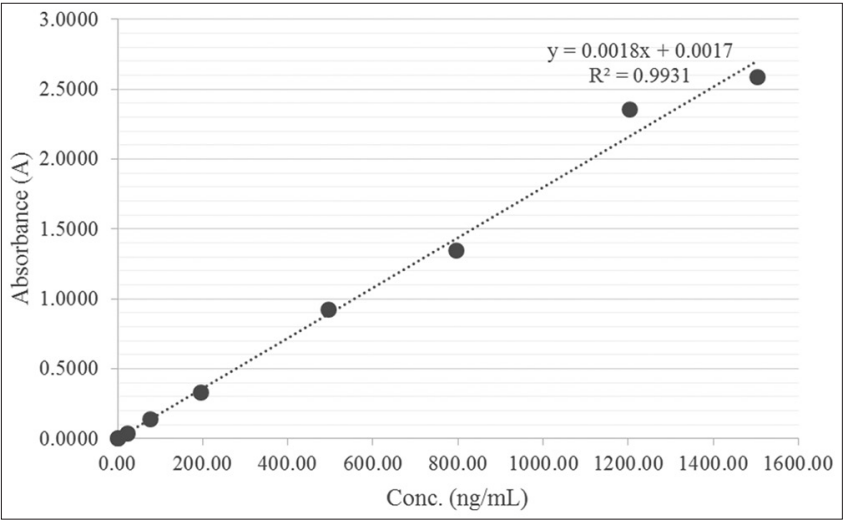

Fig. 2: Calibration curve

area ratio between ESO and the lansoprazole internal standard. The calibration curve met the accuracy requirements with $\%$ diff $\leq \pm 20 \%$ for LLOQ and $\leq \pm 15 \%$ for other concentrations. The results are presented in Table 2 and the calibration curve is shown in Fig. 2.

\section{Accuracy, precision, and recovery}

Accuracy is a measure of how close the determined concentration of the analyte is to the actual concentration in the sample, which is described by the parameter \%diff. Precision is the relative similarity of repeated measurements, which is described by the coefficient of variation (CV\%). For determining the values of these parameters, plasma ESO was analyzed at several concentrations, i.e., LLOQ QC low, QC medium, and QC high, with five replicates at each concentration. Accuracy and precision requirements were $\leq 15 \%$ for $\%$ diff and $\mathrm{CV} \%$ in QC samples and $\leq 20 \%$ for LLOQ samples. The recovery test was performed by comparing peak

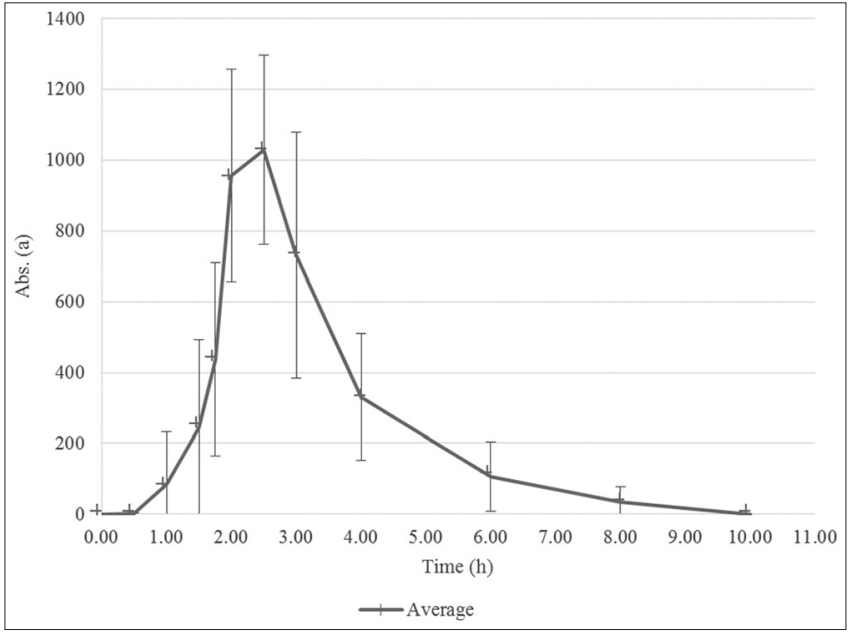

Fig. 3: Averaged pharmacokinetic profile of six subjects

areas between extracted and unextracted samples. There were no defined requirements regarding recovery as long as that the results were precise and reproducible. The accuracy and precision results are presented in Table 3 and the recovery results are shown in Table 4.

\section{Pharmacokinetic profiles of subjects' plasma}

ESO concentrations were plotted to produce a pharmacokinetic profile for each subject to determine their pharmacokinetic parameters, namely, the maximum concentration in plasma $\left(\mathrm{C}_{\text {mix }}\right)$, the maximum time $\left(t_{\max }\right), t_{1 / 2^{\prime}}, A C_{0-r^{\prime}}$ and $A C_{0-\infty}$. The values of the determined pharmacokinetic parameters for each subject are presented in Table 5, with graphs as plotted in Fig. 3. 
Table 3: Intraday accuracy and precision

\begin{tabular}{|c|c|c|c|c|c|c|c|}
\hline Concentration (ng/mL) & ESO & IS & PAR & Measurement concentration (ng/mL) & Mean $(\mathrm{ng} / \mathrm{mL}) \pm \mathrm{SD}$ & CV (\%) & \%diff \\
\hline LLOQ & 3094 & 237940 & 0.0130 & 4.89 & $4.83 \pm 0.07$ & 1.37 & -2.30 \\
\hline \multirow[t]{4}{*}{5.00} & 3290 & 253662 & 0.0130 & 4.85 & & & -2.92 \\
\hline & 3065 & 238765 & 0.0128 & 4.73 & & & -5.42 \\
\hline & 3078 & 236743 & 0.0130 & 4.88 & & & -2.33 \\
\hline & 3109 & 240726 & 0.0129 & 4.80 & & & -3.95 \\
\hline QCL & 5343 & 230798 & 0.0232 & 14.41 & $14.87 \pm 0.40$ & 2.71 & -3.95 \\
\hline \multirow{4}{*}{15.00} & 5370 & 226480 & 0.0237 & 14.93 & & & -0.44 \\
\hline & 5678 & 233749 & 0.0243 & 15.48 & & & 3.19 \\
\hline & 5340 & 225369 & 0.0237 & 14.92 & & & -0.54 \\
\hline & 5374 & 229821 & 0.0234 & 14.63 & & & -2.49 \\
\hline QCM & 171112 & 221656 & 0.7720 & 717.19 & $701.38 \pm 22.06$ & 3.15 & -4.37 \\
\hline \multirow[t]{4}{*}{750.00} & 173114 & 220363 & 0.7856 & 729.97 & & & -2.67 \\
\hline & 166318 & 222166 & 0.7486 & 695.27 & & & -7.30 \\
\hline & 161112 & 221656 & 0.7269 & 674.85 & & & -10.02 \\
\hline & 168885 & 227430 & 0.7426 & 689.61 & & & -8.05 \\
\hline $\mathrm{QCH}$ & 269448 & 230160 & 1.1707 & 1091.40 & $1079.95 \pm 16.20$ & 1.50 & -2.99 \\
\hline \multirow[t]{4}{*}{1125.00} & 262606 & 231324 & 1.1352 & 1058.11 & & & -5.95 \\
\hline & 265698 & 225714 & 1.1771 & 1097.45 & & & -2.45 \\
\hline & 265654 & 231648 & 1.1468 & 1068.97 & & & -4.98 \\
\hline & 257853 & 221792 & 1.1626 & 1083.79 & & & -3.66 \\
\hline
\end{tabular}

CV: Coefficient of variation, ESO: Esomeprazole, SD: Standard deviation, PAR: Peak area ratio, LLOQ: Lower limit of quantitation, QCL: Quality control low, QCM: Quality control medium, QCH: Quality control high

Table 4: Recovery tests results

\begin{tabular}{|c|c|c|c|c|c|c|c|c|}
\hline \multirow[t]{2}{*}{ Concentration (ng/mL) } & \multicolumn{2}{|c|}{ Extracted area $(\mu \mathrm{V} / \mathrm{s})$} & \multicolumn{2}{|c|}{ Unextracted area $(\mu \mathrm{V} / \mathrm{s})$} & \multirow[t]{2}{*}{ Recovery (\%) } & \multirow[t]{2}{*}{ Mean } & \multirow[t]{2}{*}{ SD } & \multirow[t]{2}{*}{ CV (\%) } \\
\hline & ESO & IS & ESO & IS & & & & \\
\hline QCL & 6598 & 287347 & 5643 & 220798 & 85.53 & 86.76 & 5.72 & 6.21 \\
\hline \multirow[t]{2}{*}{15.00} & 6570 & 305247 & 5778 & 223749 & 87.95 & & & \\
\hline & 6151 & 281050 & 5340 & 215369 & 86.82 & & & \\
\hline QCM & 174494 & 253290 & 171112 & 221656 & 98.06 & 99.31 & & \\
\hline \multirow{2}{*}{750.00} & 173890 & 261748 & 173114 & 220363 & 99.55 & & & \\
\hline & 163682 & 309794 & 164177 & 299434 & 100.30 & & & \\
\hline $\mathrm{QCH}$ & 291768 & 287908 & 269448 & 230160 & 92.35 & 90.42 & & \\
\hline \multirow[t]{2}{*}{1125.00} & 295822 & 241156 & 262606 & 231324 & 88.77 & & & \\
\hline & 293824 & 282644 & 264853 & 231854 & 90.14 & & & \\
\hline
\end{tabular}

CV: Coefficient of variation, ESO: Esomeprazole, SD: Standard deviation, QCL: Quality control low, QCM: Quality control medium, QCH: Quality control high

Table 5: Individual subjects' pharmacokinetic parameters

\begin{tabular}{|c|c|c|c|c|c|c|}
\hline Subject No. & $\mathrm{C}_{\max }(\mathrm{ng} / \mathrm{mL})$ & $t_{\max }(\mathbf{h})$ & $t_{1 / 2}(h)$ & $\mathrm{AUC}_{0-\mathrm{t}}(\mathrm{ng} \cdot \mathrm{h} / \mathrm{mL})$ & $\mathrm{AUC}_{0-\infty}(\mathrm{ng} \cdot \mathrm{h} / \mathrm{mL})$ & $\mathrm{AUC}_{0-\mathrm{t}} / \mathrm{AUC}_{0-\infty}(\%)$ \\
\hline E1 & 1363.34 & 3 & 2.93 & 3616.29 & 3616.29 & 100 \\
\hline E2 & 1131.25 & 2 & 1.69 & 1927.51 & 1927.51 & 100 \\
\hline E3 & 1356.26 & 2 & 1.62 & 2835.11 & 2835.11 & 100 \\
\hline $\mathrm{E} 4$ & 1425.85 & 2.5 & 1.65 & 2271.11 & 2271.11 & 100 \\
\hline E5 & 1063.11 & 2 & 1.84 & 2325.35 & 2325.35 & 100 \\
\hline E6 & 704.57 & 2 & 1.89 & 1689.27 & 1689.27 & 100 \\
\hline Mean \pm SD & $1174.06 \pm 270.92$ & $2.25 \pm 0.42$ & $1.94 \pm 0.50$ & $2444.10 \pm 693.92$ & $2444.10 \pm 693.92$ & 100 \\
\hline
\end{tabular}

CV: Coefficient of variation, SD: Standard deviation

According to the EMEA Bioanalytical Guidelines, 2011, incurred stability samples should include two concentrations in the $\mathrm{C}_{\max }$ phase and one concentration in the elimination phase in each healthy subjects' plasma. Since $t_{\max }$ varies between subjects, the ISS testing time point also varies. In the subject of $\mathrm{E} 1, \mathrm{t}_{\max }$ was at the eighth sampling time and so the ISS samples were at the seventh and eighth time points (i.e., at or close to $t_{\text {max }}$ ) and the $10^{\text {th }}$ time point (i.e., elimination phase). In the subject $\mathrm{E} 4, \mathrm{t}_{\max }$ was at the seventh sampling point, so the ISS samples were at the sixth and seventh time points (around $\mathrm{t}_{\text {max }}$ ) and the $10^{\text {th }}$ time point (elimination phase). In the remaining subjects, $t_{\max }$ was at the sixth sampling point, so the ISS samples were at the fifth, sixth, and ninth time points.

ISS

Testing was performed on the $7^{\text {th }}, 14^{\text {th }}$, and $28^{\text {th }}$ days of plasma storage and was counted from the day the pharmacokinetic profiles were created. The mean \%diff of the ISS tests is shown in Table 6 and the concentrations trends in Fig. 4.

\section{CONCLUSION}

The pharmacokinetics profiles of ESO in the plasma of six healthy subjects exhibited a $\mathrm{C}_{\max }$ range between 704.57 and $1425.85 \mathrm{ng} / \mathrm{mL}$ with an average of $1174.16 \mathrm{ng} / \mathrm{mL}$ and a mean $\mathrm{t}_{\max }$ of $2.25 \mathrm{~h}$ after a single dosage of a $40 \mathrm{mg}$ enteric-coated ESO magnesium tablet. The mean $\mathrm{AUC}_{0-\mathrm{t}}$ was $2444.10 \mathrm{ng} . \mathrm{h} / \mathrm{mL}$ with the value of $\mathrm{AUC}_{0-\mathrm{t}} / \mathrm{AUC}_{0-\infty}$ being $100 \%$ in all study subjects.

The ISS of ESO in plasma, therefore, meets the requirements up to 28 days with the highest \%diff from the average ISS sample being $6.50 \%$. 


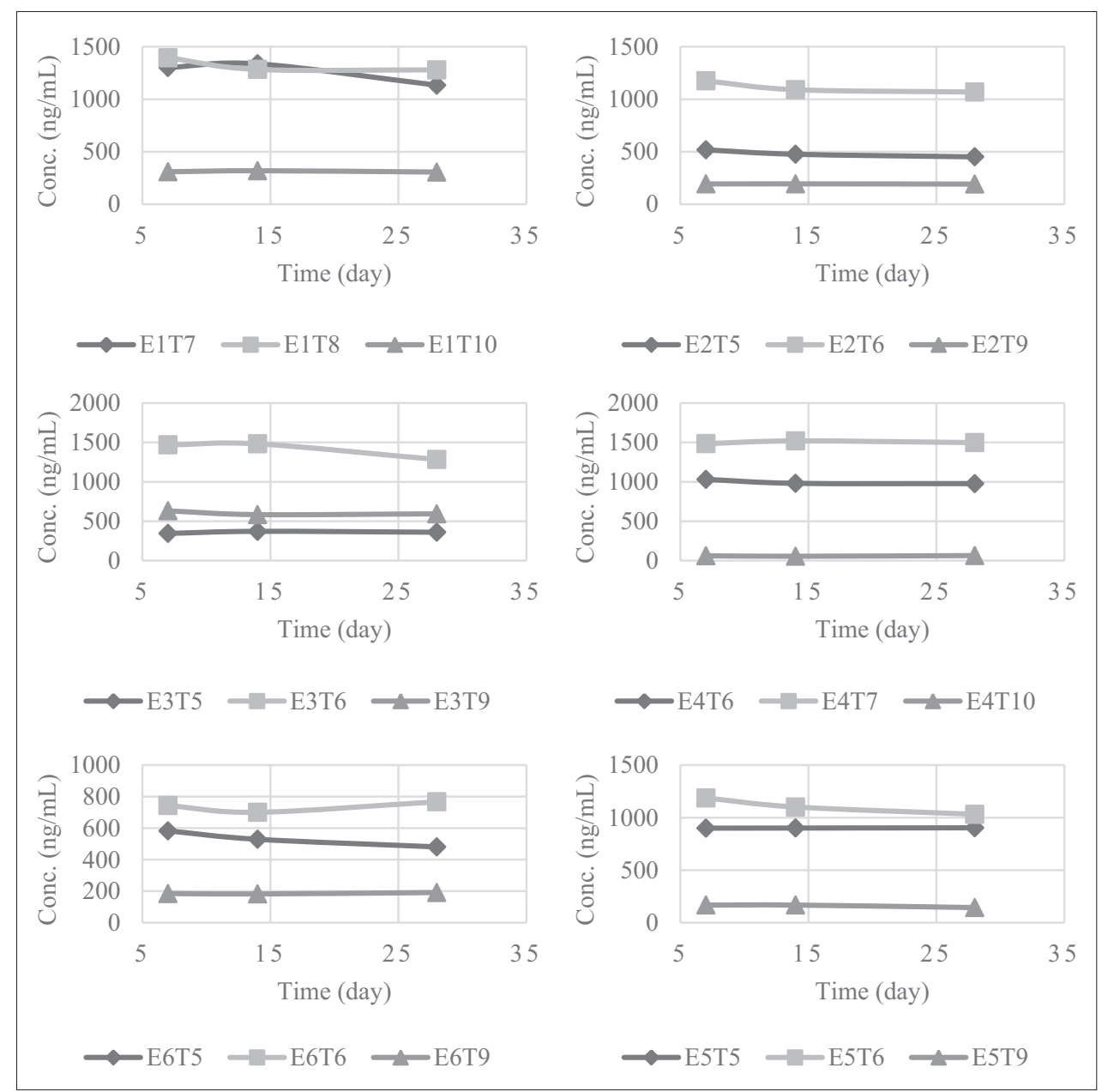

Fig. 4: Incurred sample stability trends for each subject

Table 6: Mean ISS results

\begin{tabular}{lc}
\hline ISS sample & \%diff \\
\hline Day 7 & \\
1 & 6.50 \\
2 & 5.73 \\
3 & 4.57 \\
Day 14 & \\
1 & 3.55 \\
2 & 4.84 \\
3 & 3.68 \\
Day 28 & \\
1 & 4.04 \\
2 & 4.80 \\
3 & 4.98 \\
\hline $1=1^{\text {st }} C$ & concentration $2=2^{\text {nd }} C$ concentration $3=$ Elimination phase
\end{tabular}

$1=1^{\text {st }} \mathrm{C}_{\max }$ concentration; $2=2^{\text {nd }} \mathrm{C}_{\max }$ concentration, $3=$ Elimination phase concentration. ISS: Incurred sample stability

\section{ACKNOWLEDGMENT}

This study was supported and funded through PITTA grant from Directorate of Research and Community Services, Universitas Indonesia.

\section{CONFLICTS OF INTEREST}

The authors have no conflicts of interest to declare.

\section{REFERENCES}

1. Brunton L, Lazo J, Parker K. Goodman and Gilman's: The Pharmacological Basic of Therapeutics. $11^{\text {th }}$ ed. United States of
America: The McGraw-Hill Companies, Inc.; 2006.

2. Dipiro J, Cecily V, Barbara GW, Terry L. Pharmacotherapy: A Pathophysiologic Approach. $9^{\text {th }}$ Edition. United States: The McGrawHill Companies Inc.; 2015.

3. Scott L, Dunn C, Mallarkey G, Sharpe M. Esomeprazole. Drugs 2002;62:1091-118.

4. European Medicines Agency. Guideline on Bioanalytical Method Validation. London: An Agency of the European Union; 2011.

5. Food and Drug Administration. Bioanalytical Method Validation: Guidance for Industry. America: U.S. Department of Health and Human Services, Food and Drug Administration; 2018.

6. Fluhler E, Vazvaei F, Singhal P, Vinck P, Li W, Bhatt J, et al. Repeat analysis and incurred sample reanalysis: Recommendation for best practices and harmonization from the global bioanalysis consortium harmonization team. AAPS J 2014;16:1167-74

7. Gul W, Sajid S, Hamid F, Bhatti S. Effect of acidic Ph. and heat on the degradation of omeprazole and esomeprazole. Pharm Innov 2015; 4:19-2.

8. European Medicines Agency. Nexium Control. London: An Agency of the European Union; 2013.

9. Reddy PS, Sait S, Vasudevmurthy G, Vishwanath B, Prasad V, Reddy SJ. Stability indicating simultaneous estimation of assay method for naproxen and esomeprazole in pharmaceutical formulations by RPHPLC. Der Pharm Chem 2011;3:553-64.

10. Iuga C, Bojiţă M. Stability study of omeprazole. Farmacia 2010; 58:203-10.

11. Nardi R, Masina M, Cioni G, Leandri P, Zuccheri P. Generic equivalent drugs use in internal and general medicine patients: Distrust, confusion, lack of certainties or of knowledge? Part 3. Clinical Issues. Ital J Med 2014;8:99-109.

12. Tothfalusi L, Endrenyi L. Sample sizes for designing bioequivalence studies for highly variable drugs. J Pharm Pharm Sci 2012;15:73-84. 
13. Lowes S, LeLacheur R, Shoup R, Garofolo F, Dumont I, Martinez S, et al. Recommendations on incurred sample stability (ISS) by GCC. Bioanalysis 2014;6:2385-90.
14. Harahap Y, Baskara E, Harmita H. Method validation of esomeprazole analysis in human plasma using high performance liquid chromatography photodiode array. J Young Pharm 2017;9:s24-8. 